\title{
Surface Effects in Flow Boiling of R134a in Microtubes
}

Mohamed M. Mahmoud, Tassos G. Karayiannis, David B. R. Kenning

School of Engineering and Design, Brunel University, West London, Uxbridge UB8 3PH, UK

Address correspondence to Prof. Tassos G. Karayiannis, School of Engineering and Design, Brunel University, West London, Uxbridge UB8 3PH, UK.

Email: tassos.karayiannis@ Brunel.ac.uk

Phone Number: +44 (0) 1895 267132, Fax Number: +44 (0)1895 256392 


\section{ABSTRACT}

The inner surfaces of microtubes may be influenced strongly by the process of making them due to manufacturing difficulties at these scales compared to larger ones, e.g. the surface characteristics of a seamless cold drawn tube may differ from those of a welded tube. Accordingly, flow boiling heat transfer characteristics may vary. In addition, there is no common agreement between researchers on the criteria of selecting tubes for flow boiling experiments. Instead, tubes are usually ordered from commercial suppliers, in many cases without taking into consideration the manufacturing method and its effect on the heat transfer process. This may explain some of the discrepancies in heat transfer characteristics which are found in the open literature. This paper presents a comparison between experimental flow boiling heat transfer results obtained using two different metallic tubes. The first one is a seamless cold drawn stainless steel tube of $1.1 \mathrm{~mm}$ inner diameter while the second is a welded stainless steel tube of $1.16 \mathrm{~mm}$ inner diameter. Both tubes have a heated length of 150 mm and the flow direction is vertically upwards. The tubes were heated using DC current. Other experimental conditions include: 8 bar system pressure, $300 \mathrm{~kg} / \mathrm{m}^{2} \mathrm{~s}$ mass flux, about $5 K$ inlet sub-cooling and up to 0.9 exit quality. The results are presented in the form of local heat transfer coefficient versus local quality and axial distance. Also, the boiling curves of the two tubes are discussed. The results show a significant effect of tube inner surface morphology on the heat transfer characteristics.

Keywords: flow boiling $-\mathrm{R} 134 \mathrm{a}$ - surface effects - microtubes 


\section{INTRODUCTION}

Recently, more research was devoted to investigate flow boiling characteristics in microchannels. This was motivated by the urgent need for micro-evaporators that are required for cooling high and ultra-high heat flux systems such as supercomputers, data centres and power electronics devices. Additionally, these micro-evaporators are expected to reduce refrigerant charge and also improve the COP if they are incorporated into vapour compression refrigeration systems as discussed by Qi et al. [1]. Therefore, micro-evaporators can indirectly contribute to energy savings and consequently reducing green house gases. Unfortunately, there is no common agreement between researchers on the correlations that are required for the proper design of these micro-evaporators. This arises from the lack of understanding the flow boiling fundamentals at micro-scale level. Moreover, there is a discrepancy in the open literature on the dominant flow boiling heat transfer mechanisms and the behaviour of the local heat transfer coefficient as addressed by authors [2 -5]. For example, a group of researchers such as [6 - 11] concluded nucleate boiling as a dominant mechanism while [12 - 14] concluded convective boiling as a prevailing mechanism. Another group such as [15 - 19] concluded both nucleate and convective boiling mechanisms. However, the reasons behind this discrepancy are not yet understood; one possible reason could be the occurrence of stable versus unstable boiling as found by Consolini and Thome [20] and Ohta et al. [21]. During unstable boiling, the heat transfer coefficient was found to be independent of local vapour quality while during stable boiling the heat transfer coefficient was found to increase with quality in the high quality region. Another possible reason could be the inner surface characteristics of the investigated channels that may influence the behaviour of the nucleation process. It is well known that surface characteristics strongly influence nucleation in pool boiling and consequently heat transfer performance. For example, Saiz Jabardo et al. [22] recently reported a significant effect of boiling surface material and roughness on nucleate pool boiling heat transfer of R134a and R123. Of the examined materials, the stainless steel surface was found to have the worst thermal performance compared to copper and brass due to its lowest ductility that influences its surface finish. Since the key principles of nucleation in flow boiling are originally "borrowed" from pool boiling, the present authors expected that flow boiling heat transfer characteristics will be influenced strongly by the microstructure of the inner surface of the channel. In addition to that, the number of nucleation sites in micro-tubes compared to large diameter tubes may represent another avenue in explaining the disparity in the published heat transfer results. In other words, the small number of nucleation sites in microtubes, compared 
to larger tubes, makes the differences in surface characteristics even more important. Therefore, specifying the manufacturing process and inner surface characteristics is very important in flow boiling studies where it may contribute in interpreting the wide scatter in the published flow boiling heat transfer data at micro-scale.

Some researchers such as [20] and [23 - 27] investigated flow boiling heat transfer of $\mathrm{R} 134 \mathrm{a}$ in single micro-tubes made of stainless steel with inner diameters of about 0.5 and 1 $\mathrm{mm}$. They did not report any information about the manufacturing process of the investigated tubes except the experimental study by the current research group [25] and [26] who used seamless cold drawn stainless steel tubes. Kandlikar and Spiesman [28] investigated the effect of surface finish on flow boiling heat transfer of sub-cooled water in a channel of $3 \times$ $40 \mathrm{~mm}$ cross section. The channel was horizontal with a rod heater inserted vertically such that the top surface of the heater formed the bottom surface of the channel. Four rod heaters of $10 \mathrm{~mm}$ diameter made of aluminium with different surface characteristics were investigated. They have found that, the variations of surface roughness from 0.188 to 3.064 $\mu \mathrm{m}$ significantly affected the measured wall superheat and consequently the heat transfer coefficient. The rougher the surface, the lower the wall superheat (the higher the heat transfer coefficient). Figure 1 shows the trends of the local heat transfer coefficient versus local vapour quality that were measured by researchers [20] and [23 - 27] using stainless steel tubes of diameters ranging from 0.5 to $1 \mathrm{~mm}$ and R134a as a test fluid. Owhaib et al. [23], Martin-Callizo et al. [24], Shiferaw et al. [25] and Mahmoud et al. [26] investigated flow boiling heat transfer in vertical tubes made of grade AISI 316 while Consolini and Thome [20] and Ong and Thome [27] investigated horizontal tubes made of grade AISI 304. These researchers agreed on the effect of heat flux in the low to intermediate quality region where they found that the heat transfer coefficient increases strongly with increasing heat flux with little dependence on vapour quality. Conventionally, this can be interpreted as a dominance of nucleate boiling. However, Fig, 1 shows that there is no complete agreement on the trends of the local heat transfer coefficient at different heat fluxes. For the $1 \mathrm{~mm}$ tube at low heat flux values, it is clear that different trends were obtained by Owhaib et al. [23] (Fig. 1a), Ong and Thome [27] (Fig. 1b) and Shiferaw et al. [25] (Fig. 1c). In Fig. 1a, the heat transfer coefficient rapidly decreased from its maximum value at quality of about zero and subsequently showed a slight decreasing behaviour with increasing quality. While in Fig. 1b and $1 \mathrm{c}$, the heat transfer coefficient showed an increasing trend with quality towards the tube exit. Another difference was the occurrence of dryout, which occurred at low heat flux in Fig. 1a $\left(34 \mathrm{~kW} / \mathrm{m}^{2}\right)$, delayed to higher heat flux value of $53 \mathrm{~kW} / \mathrm{m}^{2}$ in Fig. 1c and no dryout was 
observed in Fig. $1 \mathrm{~b}$ for $\mathrm{x} \leq 0.7$. The variations in dryout heat flux may be arising from the small differences in the heated lengths investigated in theses studies. Inspecting the trends in the $0.5 \mathrm{~mm}$ tubes, similar conclusion can be drawn where three different trends from three different studies were observed. In the study of Martin-Callizo et al. [24] (Fig. 1d), the heat transfer coefficient showed a fluctuating trend with local quality and dryout occurred at high heat fluxes while in the study of Consolini and Thome [20] (Fig. 1e) the heat transfer coefficient increased slightly with quality towards the tube exit before it decreases at the last thermocouple location. Contrary to that, Mahmoud et al. [26] (Fig. 1f) found that the heat transfer coefficient decreases from its highest value at quality of about zero and remains constant over a narrow range of local qualities then all the lines merged together into one curve showing increasing trend with increasing vapour quality.

It is known that stainless steel tubes are commercially available in two forms; seamless cold drawn and welded tubes. Seamless tubes are usually manufactured by hot extrusion and drawn processes while welded tubes are fabricated from a strip that is rolled to the required size then welded. As mentioned above, there is no agreement between research groups on the criteria of tube selection for testing and the manufacturing process is usually not considered when ordering tubes from suppliers. For instance, Qi et al. [29] investigated flow boiling of liquid nitrogen in stainless steel micro-tubes that are used to fabricate medical injection needles and the current research group ordered tubes from one of the cryogenics companies. This paper focuses on the flow boiling heat transfer characteristics of tubes manufactured by using two different processes, with the objective of identifying and detecting any differences in the performance.

\section{EXPERIMENTAL FACILITY AND DATA REDUCTION}

An experimental facility was designed and constructed to investigate flow boiling characteristics using a wide range of tube diameters. The detailed description of the test rig can be found in Huo et al. [30]. In the tests described in this paper, two stainless steel tubes manufactured by two different methods were investigated. The first is a seamless cold drawn tube and made of stainless steel AISI316 with inner diameter of $1.1 \mathrm{~mm}$. The second is welded tube and made of stainless steel AISI304 with inner diameter of $1.16 \mathrm{~mm}$. The details of the test section are shown schematically in Fig. 2. Each test section consists of an adiabatic calming section with length of $150 \mathrm{~mm}$, heated section with length of $150 \mathrm{~mm}$ and a borosilicate visualization section with length of $100 \mathrm{~mm}$ and same inner diameter as the 
investigated tube. After the visualization section, another adiabatic calming section of 100 $\mathrm{mm}$ length and $1.1 \mathrm{~mm}$ diameter was added to avoid the effect of sudden area enlargement on the observed flow patterns at the upstream location. The heated section was directly heated by passing a DC current through two copper electrodes that were welded at the inlet and outlet. The supplied power was directly measured between the test section electrodes using a Yokogawa power meter WT110 with accuracy provided by the manufacturer, $\pm 0.29 \%$. This is to exclude the voltage drop across the connections between the power supply and the test section electrodes. The heated section was electrically isolated from the other parts of the system by using a short piece of PTFE tube as shown in Fig. 2. The PTFE tube connections were tightened by clips. The outer surface temperature was locally measured by K-type thermocouples (T1 to Tn on Fig. 2) with mean absolute error of $\pm 0.22 \mathrm{~K}$ attached at $10 \mathrm{~mm}$ intervals. In the welded tube, fourteen thermocouples were attached to the surface with the first and last thermocouples attached $10 \mathrm{~mm}$ away from the electrodes. Thirteen thermocouples were attached on the surface of the seamless cold drawn tube with mean absolute error of $\pm 0.18 \mathrm{~K}$ and the first and last thermocouples were attached $15 \mathrm{~mm}$ away from the electrodes. The first and last thermocouples were located away from the electrodes to avoid the effect of heat losses at the electrodes. All thermocouples were attached to the surface by using an electrically insulating but thermally conducting epoxy. Fluid temperature and pressure were measured at the test section inlet and outlet using T-type thermocouples with accuracy of $\pm 0.1 \mathrm{~K}$ and pressure transducers with accuracy of $\pm 0.32 \%$ respectively. The pressure drop was directly measured between the test section inlet and outlet using a differential pressure transducer (PX771A-025DI supplied by Omega) with accuracy of \pm 0.1 $\%$. It is worth noting that, there are no flow restrictions at the test section inlet and outlet. A Phantom V4 digital high speed camera with 1000 frame/s and resolution of $512 \times 512$ pixels was used for flow visualization. The data were monitored through a Labview program at a frequency of $1 \mathrm{~Hz}$ using three data loggers: Solartron model SI35951E (two) and SI35351C. All the data were recorded for $90 \mathrm{sec}$ after attaining steady state and the sample of the 90 data points was averaged and used in the calculations. Steady states are conditions to be reached when the signals reach their minimum values of oscillations. Figure 3 depicts one example for the oscillations in the mass flow rate and wall temperature as a function of heat flux at 6 bar system pressure and $300 \mathrm{~kg} / \mathrm{m}^{2} \mathrm{~s}$ mass flux. At zero heat flux, the oscillations in the mass flow rate and wall temperature were $3.97 \%$ and $0.35 \%$ of the mean value, respectively which are very small and confirm that the facility has reached steady state. At heat flux value just before the occurrence of dryout $\left(q=97 \mathrm{~kW} / \mathrm{m}^{2}\right)$, the oscillations in the mass flow rate 
and wall temperature slightly increased to $5.5 \%$ and $0.63 \%$, respectively. In other words, the experimental data in the present study are collected under steady state conditions.

As the flow is hydrodynamically developed in the calming section and there are no inlet or outlet restrictions, the classical equation of fully developed flow can directly be applied to calculate the single phase fanning friction factor as:

$$
f=\frac{\pi^{2}}{32} \frac{\rho \Delta P_{m} D_{i}^{5}}{\dot{m}^{2} L_{p}}
$$

The applied heat flux is calculated as:

$$
q^{\prime \prime}=\frac{V I-Q_{\text {Loss }}}{A_{s}}
$$

The heat loss $Q_{\text {loss }}$ in boiling experiments was estimated from single phase runs which were carried out just before boiling. The local inner surface temperature of the tube wall can be calculated by solving the steady one dimensional heat conduction equation with internal heat generation and is given by Eq. (3). From an energy balance the local fluid temperature can be calculated from Eq. (4).

$$
\begin{gathered}
T_{w i}(z)=T_{w, o}(z)-\left(\frac{q_{v} D_{o}^{2}}{16 k_{s}}\right)\left[1-\left(\frac{D_{i}}{D_{o}}\right)^{2}-2 \ln \left(\frac{D_{o}}{D_{i}}\right)\right] \\
T_{f}(z)=T_{f, i n}+\frac{q^{\prime \prime} \pi D_{i}}{G A_{c} c_{p}} z
\end{gathered}
$$

The local single phase heat transfer coefficient was calculated from Eq. (5) and the local $\mathrm{Nu}$ number is given by Eq. (6).

$$
\begin{gathered}
\alpha_{s p}(z)=\frac{q^{\prime \prime}}{T_{w i}(z)-T_{f}(z)} \\
N u(z)=\frac{\alpha_{s p}(z) D_{i}}{k_{f}}
\end{gathered}
$$

The average $\mathrm{Nu}$ number is the integral with distance of $\mathrm{Nu}(\mathrm{z})$. In two phase flow, the local flow boiling heat transfer coefficient was calculated from:

$$
\alpha_{t p}(z)=\frac{q^{\prime \prime}}{T_{w i}(z)-T_{s a t}(z)}
$$

The local saturation temperature is calculated from the local pressure with the assumption that the two phase pressure drop along the tube is linear. As the flow enters the test section under sub-cooled conditions and the tube length is relatively short, the length of the sub- 
cooled section should be taken into consideration. From an energy balance, the sub-cooled length can be found by iteration using Eqs. (8) - (10).

$$
\begin{gathered}
z_{\text {sub }}=\frac{G A_{c} c_{p}\left(T_{\text {sat }}\left(z_{\text {sub }}\right)-T_{f, \text { in }}\right)}{q^{\prime \prime} \pi D_{i}} \\
\Delta P_{s p}=\frac{G^{2}}{\rho_{L}} \frac{2 f}{D_{i}} z_{\text {sub }} \\
P\left(z_{\text {sub }}\right)=P_{\text {in }}-\Delta P_{s p} \\
\Delta P_{t p}=\Delta P_{m}-\Delta P_{s p} \\
P(z)=P\left(z_{\text {sub }}\right)-\frac{z-z_{\text {sub }}}{L_{h}-z_{\text {sub }}} \Delta P_{t p}
\end{gathered}
$$

where $\Delta \mathrm{P}_{\mathrm{m}}$ is the total pressure drop measured across the test section. The local vapour quality can be calculated as:

$$
x(z)=\frac{h(z)-h_{f}(z)}{h_{f g}(z)}
$$

The local enthalpy of saturated liquid and the local latent heat are calculated based on the local pressure given by Eq. (12). The local enthalpy at position z can be calculated from an energy balance up to this position as:

$$
h(z)=h_{i n}+\frac{q^{\prime \prime} \pi D_{i} z}{G A_{c}}
$$

All instruments except the two Yokogawa power meters were calibrated in-house and the accuracies were given above. Experimental uncertainties were then calculated based on the method given in Coleman and Steele [31] and estimated as: $14.5 \%$ for the single phase friction factor, $7 \%$ for the single phase heat transfer coefficient, and $6 \%$ for the local flow boiling heat transfer coefficient. Single phase validation was conducted using the two test tubes before commencing the boiling experiments. Figure 4 depicts the measured single phase friction factor and heat transfer coefficient compared to the conventional macro-scale theory. It is clear from the figure that the measured friction factor in the two tubes is in a good agreement with the laminar flow theory and Blasius's equation [32]. The single phase heat transfer coefficient in the laminar region for the two tubes agreed reasonably with the correlation of Shah and London [33] for hydrodynamically developed/thermally developing flow. In the turbulent region, the heat transfer coefficient for the welded tube agreed with Dittus and Boelter's equation [34] and with Petukhov's equation [35] up to $\operatorname{Re}=\sim 5000$. After this value, the measured coefficient is higher than the predicted values and the 
deviation increases as Reynolds number increases. This could be due to the presence of local anomalies in the surface of this tube as will be discussed latter. This anomaly may create additional local turbulence and thus may result in heat transfer enhancement when the Reynolds number increases. The agreement of the experimental results of the cold drawn tube was very good, with the results being only marginally lower than those predicted by the equations of Dituus and Boelter [34] and Petukhov [35].

\section{RESULTS}

In this section, the experimental flow boiling heat transfer results obtained using welded and seamless cold drawn stainless steel tubes of similar diameter and heated lengths will be presented and discussed. Other experimental conditions include: $\mathrm{G}=300 \mathrm{~kg} / \mathrm{m}^{2} \mathrm{~s}, \mathrm{P}=8 \mathrm{bar}$, $q=13-102 \mathrm{~kW} / \mathrm{m}^{2}$, exit quality up to 0.9 and $\Delta \mathrm{T}_{\text {sub }}=5 \mathrm{~K}$. Section 3.1 presents the effect of heat and mass flux on the behaviour of the local flow boiling heat transfer coefficient while section 3.2 presents the measured boiling curves.

\subsection{Flow Boiling Heat Transfer Coefficient}

Figure 5 depicts the effect of heat flux on the local flow boiling heat transfer coefficient for the welded tube as a function of local vapour quality (Fig. 5a) and axial distance (Fig. 5b). It is clear from this figure that, the heat transfer coefficient shows a peculiar behaviour that was not observed before. The $\alpha-x$ plot (Fig. 5a), shows for most heat fluxes that after thermocouple location No. 4 the heat transfer coefficient decreases rapidly to a minimum value at thermocouple location No. 8 with approximately similar slope. After this minimum, the heat transfer coefficient increases rapidly with quality before it decreases again at the last thermocouple location. In the entry region, the heat transfer coefficient jumped from the single phase value and peaked at a value of quality near zero due to the onset of boiling. It is worth noting that, the observed drop at the last thermocouple location seems to be due to factors other than normal dryout because this behaviour was observed even at the lowest heat fluxes where the quality is very low for dryout to occur (see Fig. 5a). Additionally, the effect of heat flux is not clear from the $\alpha-x$ plot where at some quality values (intermediate qualities) the coefficient decreases with increasing heat flux while at very low qualities it increases with heat flux for some heat flux values. In other words, the heat flux effect seems difficult to detect in this plot. However, re-plotting the heat transfer coefficient versus the axial thermocouple location (Fig. 5b) instead of vapour quality demonstrated some minimal 
effect of heat flux but for some regions all the lines approximately merged together $(\mathrm{z}=0.04$ $-0.06 \mathrm{~m}$ and $\mathrm{z}>0.12 \mathrm{~m})$.

Figure 6 shows the effect of heat flux on the local heat transfer coefficient in the seamless cold drawn tube. It is seen from this figure that the behaviour of the heat transfer behaviour is completely different compared to that obtained using the welded tube. It is seen from Fig. 6a that the heat transfer coefficient jumps from its single phase value and peaks at quality values very close to zero then it remains approximately constant with local quality. Contrary to Fig. 5, the effect of heat flux is very clear from both the $\alpha-x$ and $\alpha-z$ plots where the heat transfer coefficient increases with increasing heat flux. Since the heat flux effect is not clear in Fig. 5 for the welded tube, the heat transfer coefficient was re-plotted versus heat flux at three axial locations in Fig. 7a and the same thing was done in Fig. 7b for the seamless tube for the sake of comparison. Figure 7a shows that, the effect of heat flux depends on axial location for the welded tube. At the entry region, the heat transfer coefficient increased with heat flux up to $\mathrm{q}=49.2 \mathrm{~kW} / \mathrm{m}^{2}$ after which it constantly decreased with heat flux. At the exit, the heat transfer coefficient increased with heat flux up to $\mathrm{q}=26.4 \mathrm{~kW} / \mathrm{m}^{2}$ then it continuously decreased with increasing heat flux. At the middle of the tube, the heat transfer coefficient increased linearly with heat flux. On the contrary, Fig. 7b shows that the heat flux effect is almost similar at all locations in the seamless tube where it increases with heat flux.

Figure 8 illustrates the effect of mass flux on the local heat transfer coefficient at $q=41$ $\mathrm{kW} / \mathrm{m}^{2}$ for the welded tube (Fig. 8a) and for the seamless tube (Fig. 8b). Inspecting Fig. 8a, again the mass flux effect seems complex and difficult to deduce from the $\alpha-x$ plot, while the $\alpha-z$ plot shows a rather insignificant effect. The $\alpha-x$ and $\alpha-z$ plots of the seamless tube do not show any mass flux effect and all the lines merge into a single line. Figure 9 shows the local heat transfer coefficient plotted against mass flux at three axial locations for both tubes. Applying the conventional criterion for the controlling mechanism (the heat transfer coefficient depends on $q$ but independent of $x$ and $G$ ), it can be concluded from Fig. 6a, Fig. $7 \mathrm{~b}$ and Fig. $9 \mathrm{~b}$ that heat transfer is dominated by the nucleate boiling mechanism in the seamless cold drawn tube where the heat transfer coefficient does not show any dependence on local vapour quality and mass flux while it increases with heat flux. On the other hand, the controlling mechanism in the welded tube is not clear. Examination of Fig. 5a, Fig. 7a and Fig. 9a shows some features of nucleate boiling in the mid section of the welded tube, i.e. the coefficient depends on heat flux and insignificantly depends on quality and mass flux. On the 
other hand, the last section towards the exit demonstrates some features of convective boiling, i.e. the coefficient increases with vapour quality and mass flux with little dependence on heat flux.

\subsection{Boiling Curve}

Figure 10 compares the boiling curves of the welded and seamless tubes plotted at three axial locations with increasing heat flux in small increments. The first location represents the entry region while the second and third locations represent the middle and exit regions, respectively. In the entry region (Fig. 10a), the results of the two tubes agreed on the high wall superheat required for the onset of nucleate boiling, i.e. it reached $14.2 \mathrm{~K}$ in the welded tube and $18 \mathrm{~K}$ in the seamless tube. Also, the onset of nucleate boiling in the welded tube occurred at a relatively lower heat flux value of $9.4 \mathrm{~kW} / \mathrm{m}^{2}$ compared to $12.9 \mathrm{~kW} / \mathrm{m}^{2}$ in the seamless tube. It is interesting to note that, after boiling incipience the two curves merged together into one single line with the wall superheat decreasing with heat flux up to $\mathrm{q} \approx 25$ $\mathrm{kW} / \mathrm{m}^{2}$. After this heat flux value, the two curves separate and behave in a different way. At $\mathrm{q}$ $=25 \mathrm{~kW} / \mathrm{m}^{2}$, the curve of the seamless cold drawn tube shows fully developed nucleate boiling and wall superheat increased by $2.85 \mathrm{~K}$ when q was increased from 25 to $101 \mathrm{~kW} / \mathrm{m}^{2}$. In the welded tube, the fully developed nucleate boiling established at $\mathrm{q}=41 \mathrm{~kW} / \mathrm{m}^{2}$ and wall superheat increased by $2.3 \mathrm{~K}$ when q was increased from 41 to $98 \mathrm{~kW} / \mathrm{m}^{2}$. At the mid location (Fig. 10b), the welded tube required $17.4 \mathrm{~K}$ wall superheat for the onset of nucleate boiling which started normally in the seamless tube at a wall superheat of only $3.7 \mathrm{~K}$. In this mid location, after the onset of nucleate boiling, the two curves merged into one single curve with some small difference appearing after $\mathrm{q}=70 \mathrm{~kW} / \mathrm{m}^{2}$. At the location close to the exit (Fig. 10c), the required wall superheat for the onset of nucleate boiling remained high at $17.4 \mathrm{~K}$ for the welded tube while it reached only $3.2 \mathrm{~K}$ for the seamless tube. Additionally, at the onset of nucleate boiling, the wall superheat dropped from $17.4 \mathrm{~K}$ to $0.44 \mathrm{~K}$ in the welded tube while it dropped from $3.2 \mathrm{~K}$ to $1.89 \mathrm{~K}$ in the seamless tube. After the onset of nucleate boiling, the two curves showed fully developed nucleate boiling with the wall superheat in the welded tube much lower than that in the seamless tube for a given heat flux. It may be concluded from these figures that, triggering fully developed nucleate boiling in the seamless tube required high wall superheat only in the entry region where nucleation stability may be influenced by the inlet sub-cooling while the welded tube required high wall superheat at all locations along the tube. It is worth noting that, Fig. 10d shows the flow patterns observed at boiling 
incipience and onset of nucleate boiling in the two tubes. The difference between boiling incipience and onset of nucleate boiling in the present study is that at boiling incipience bubbles appeared in the observation section while the wall superheat is still high, i.e. $17.4 \mathrm{~K}$ in the welded tube and $3.2 \mathrm{~K}$ in the seamless tube. On the other hand, the onset of nucleate boiling was identified when the wall superheat dropped from its maximum to its minimum value. Pictures No. 1 and 3 illustrate the first bubbles that appeared in the observation section at boiling incipience for the seamless and welded tubes, respectively. In the seamless tube, the first bubbles appeared at a heat flux value of $5.3 \mathrm{~kW} / \mathrm{m}^{2}$ as a mixture consisting of short vapour slugs and small bubbles that are smaller than the tube diameter with a neck similar to the nucleating bubble on the cavity mouth before departure. This behaviour in the seamless tube suggests the activation of a few nucleation sites close to the tube exit. By contrast, the first bubbles appeared in the welded tube at relatively higher heat flux compared to the seamless tube $\left(\mathrm{q}=9.4 \mathrm{~kW} / \mathrm{m}^{2}\right)$ as a well-defined confined bubble/slug flow directly. It is worth noting that, these first bubbles appeared in both tubes while the wall temperature was still showing single phase trend. Pictures No. 2 and 4 show the flow patterns at the onset of fully developed nucleate boiling, i.e. wall superheat drops from maximum to minimum. The flow patterns at that condition were very similar in the two tubes, where long vapour slugs appeared with the presence of some tiny bubbles in the liquid slug between the consecutive vapour slugs.

\section{DISCUSSION}

The above results show a clear difference in heat transfer behaviour between the seamless cold drawn tube and welded tube. Since the two investigated tubes are similar in dimensions, design and instrumentation, the difference in heat transfer results is believed to be caused by the difference in the inner surface characteristics as a result of the manufacturing process. As mentioned earlier, one of the problems in flow boiling experimental studies in micro-tubes is that the investigated tubes are usually ordered from suppliers without taking the manufacturing process into consideration. Until now, there is no documentation of the effect of manufacturing process on the inner surface of the tube, particularly when the size becomes very small. This may be due to the fact that most people validate their test sections only by single phase flow, which is not enough to extend for flow boiling studies. This paper confirms this point where the measured single phase friction factor in the welded tube agreed well with the conventional theory while peculiar behaviour was observed in flow boiling. For 
this reason, a sample of each tube (cut from the length from which the test sections were designed) was chopped into two halves and the inner surface was inspected using the scanning electron microscope (SEM) as depicted in Fig. 11. As it is seen in Fig. 11a, the inner surface of the welded tube looks smooth with the existence of some fragments or debris on the surface. The smoothness of this surface may explain the high wall superheat that is required for the onset of nucleate boiling at all axial locations along the tube as presented above in Fig. 10. Figure 11 may also explain the small effect of heat flux on the local flow boiling heat transfer coefficient along a major section of the welded tube as presented in Fig. 5. This may be attributed to the scarcity of active nucleation sites in this tube where heat flux will have an effect when the surface is rough and the boiling regime is nucleate boiling. Moreover, the shape of the observed fragments is not regular and nucleation process will depend on whether the debris forms a cavity-like shape or not. In other words, the heat transfer behaviour will depend on the shape and number of debris and also their local distribution along the heated section of the tube. By contrast, Fig. 11b depicts a completely different texture for the inner surface of the seamless cold drawn tube, which looks like as if it has random scratches or channels that seem uniformly distributed along the tube. It is interesting to note that Fig. 11 is consistent with the manufacturing process. It is known that welded tubes are usually manufactured by rolling a strip of stainless steel into the required diameter and applying a welding process on the same rolling machine. Accordingly, if the original metal sheet is already smooth, the inner surface of the formed tube may be similar to the one formed in Fig.11a. On the other hand, seamless tubes are usually manufactured by hot extrusion to form the hollow tube first followed by a number of cold drawn processes to reduce the diameter to the required size. In the production of thin seamless tubes, an inner support (floating plug) is usually used during the drawing process, which may create the longitudinal random scratches on the inner surface shown in Fig. 11b. Additionally, these random scratches together seem to form the sort of cavities that are required for the nucleation process.

In addition to the above pictures of Fig. 11, Fig. 12 presents the trend of the measured wall temperature versus axial distance under single phase and boiling conditions which confirms the difference of the inner surface in the two tubes. Figure 12a shows, at very low Reynolds number and similar conditions, that the trend of the wall temperature in the two tubes is the same. With increasing Reynolds number, a sudden local drop in the wall temperature was observed in the two tubes but at two different locations $(z=0.1$ for the welded tube and $z=$ 
0.065 for the seamless tube) see Fig. 12b. After this drop, the wall temperature increased linearly with axial distance. It is worth noting that the location of the temperature drop moved upstream when Reynolds number increased further until it disappeared in the fully developed turbulent flow regime. This behaviour might arise from the existence of local turbulence induced by the local debris in the welded tube and the local scratches in the seamless tube. Accordingly, possible local heat transfer enhancement at these locations results in this local temperature drop. Additionally, Fig. 12c depicts the wall temperature at similar heat flux for the two tubes under boiling conditions. It is clear that, the two tubes agreed on the middle section while a significant difference is observed in the first and last sections of the tubes.

\section{REPRODUCIBAILITY OF EXPERIMENTS}

The reproducibility of the experimental results is one of the issues that may be raised in flow boiling studies particularly when the diameter becomes very small. As the tube diameter decreases, the number of nucleation sites per unit length is expected to decrease which may be stable or not. Thus, it is very important to know whether there is any disparity in the measured local heat transfer coefficient from day to day. In the current study, the experiments were repeated at one selected experimental condition over a time period from two weeks to one month. Figure 13 depicts the reproducibility of the data in the welded and seamless tube at $P=8$ bar and $G=300 \mathrm{~kg} / \mathrm{m}^{2}$ s. The figure shows that the data of the seamless cold drawn tube are reasonably repeatable within the experimental uncertainty. In the welded tube, the reproducibility of the data was also fairly good with only some limited number of locations showing marked differences while the trend was identical.

\section{CONCLUSIONS}

In this paper, flow boiling heat transfer of R-134a was investigated using two stainless steel tubes of similar diameter and heated length but manufactured by two different methods in order to investigate the effect of the inner surface on heat transfer rates. The first tube was welded while the second was a seamless cold drawn tube. The experiments were conducted at $\mathrm{G}=300 \mathrm{~kg} / \mathrm{m}^{2} \mathrm{~s}, \mathrm{P}=8$ bar and low inlet sub-cooling of $5 \mathrm{~K}$. It can be concluded that:

1. The flow boiling characteristics in the welded tube were completely different from those in the seamless cold drawn tube. In the seamless tube, the heat transfer process was dominated by the nucleate boiling mechanism while the welded tube 
does not show a clear dominant mechanism, i.e. it experienced some features of nucleate and convective boiling. However, there is some agreement on the behaviour along a short length at the mid location of both tubes.

2. The manufacturing process significantly influences the inner surface of the microtubes. This was confirmed by the SEM pictures and also the local heat transfer behaviour. This difference in surface characteristics may explain the peculiar heat transfer behaviour in the welded tube.

3. Validating the inner surface of the manufactured micro-tubes by single phase flow only may not be enough for using these tubes for the design of micro-evaporators. In addition to single phase flow, the inner surface characteristics should be taken into consideration, i.e. at least clearly stated in the reports.

4. Since the inner surface of the welded tube seems too smooth, the possibility of having sufficient number of nucleation sites of uniform distribution along the tube is very small. This may explain the fact that the heat transfer coefficient is not uniform along the welded tube, which would have been the case if a large number of nucleation sites resulted in nucleate boiling. On the contrary, the seamless cold drawn tubes offer a surface with a larger number of nucleation sites.

We are currently investigating the effect of tube heated length on the local flow boiling heat transfer characteristics. This factor plus the surface characteristics may contribute in explaining the large disparities in the published heat transfer results in the open literature.

\section{REFERENCES}

[1] Qi, Z. Zhao, Y., Chen, J. (2010), Performance enhancement study of mobile air conditioning system using microchannel heat exchangers, Int. J. of Refrigeration, 33,301 312.

[2] Watel, J. (2003), Review of saturated flow boiling in small passages of compact heatexchangers, Int. J. of Thermal Sciences, 42, $107-140$.

[3] Vlasie, C., Macchi, H.., Guilpart, J., Agostini, B. (2004), Flow boiling in small diameter channels, Int. J. of Refrigeration, 27, $191-201$.

[4] Thome, J. R. (2006), State-of-the-art overview of boiling and two phase flows in microchannels, Heat Transfer Engineering, 27(9), 4-19. 
[5] Ribatski, G., Wojtan, L., Thome, J. R. (2006), An analysis of experimental data and prediction methods for two-phase frictional pressure drop and flow boiling heat transfer in micro-scale channels, Experimental Thermal and Fluid Science, 31, 1-19.

[6] G.M. Lazarek, S.H. Black, Evaporative heat transfer, pressure drop and critical heat flux in a small vertical tube with R113, Int. J. Heat Mass Transfer, 25(7):945-960, 1982.

[7] M.W. Wambsganss, D.M. France, J.A. Jendraejczyk, T.N. Tran, Boiling heat transfer in a horizontal small-diameter tube, J. of Heat Transfer, 115:963-972, 1993.

[8] Z.Y. Bao, D.F. Fletcher, B.S. Haynes, Flow boiling heat transfer of Freon R11 and HCFC123 in narrow passages, In. J. Heat Mass Transfer, 43: 3347-3358, 2000.

[9] B. Agostini, A. Bontemps, Vertical flow boiling of refrigerant R134a in small channels, In. J. Heat Fluid Flow, 26(2):296-306, 2005.

[10] Martin-Callizo, C., Ali, R., Palm, B, New experimental results on flow boiling of R134a in a vertical microchannel, UK. Heat Transfer Conference Proceedings, Edinburgh 10-11 September, 2007.

[11] Bertsch, S.S., Groll, E.A., Garimella, S.V., Effects of heat flux, mass flux, vapor quality, and saturation temperature on flow boiling heat transfer in microchannels, Int. J. of Multiphase Flow, 35 (2), pp. 142-154, 2009.

[12] B .Sumith, F. Kaminaga, K. Matsumura, Saturated flow boiling of water in a vertical small diameter tube, Experimental Thermal Fluid Science, 27:789-801, 2003.

[13] H. J. Lee, S.Y. Lee, Heat transfer correlation for boiling flows in small rectangular horizontal channels with low aspect ratios, Int. J. Multiphase Flow, 27:2043-2062, 2001.

[14] Lee, J., Mudawar, I. 2005, Two-phase flow in high heat flux microchannel heat sink for refrigeration cooling applications: Part II heat transfer characteristics, Int. J. Heat Mass Transfer, 48, pp. $941-955$.

[15] Yan Y., Lin T. 1998, Evaporation heat transfer and pressure drop of refrigerant R134a in a small pipe, Int. J. of Heat and Mass Transfer, 41:4183 - 4194.

[16] Lin, S., Kew, P.A., Cornwell, K., 2001, Two-phase heat transfer to a refrigerant in a $1 \mathrm{~mm}$ diameter tube, Int. J. Refrigeration, Vol. 24, pp. 51-56.

[17] Saitoh, S., Daiguji, H., Hihara, E. 2005, Effect of tube diameter on boiling heat transfer of R134a in horizontal small diameter tubes, Int. J. Heat Mass Transfer, 48, pp. 4973 - 4984.

[18] Chin L. O., Thome J. R. 2009, Flow boiling heat transfer of R134a, R236fa and R245fa in a horizontal $1.03 \mathrm{~mm}$ circular channel, Experimental Thermal and Fluid Science, 33:651 663. 
[19] Mahmoud, M.M., Kenning, D.B.R., Karayiannis, T.G., Single and two phase heat transfer and pressure drop in a $0.52 \mathrm{~mm}$ vertical metallic tube, $7^{\text {th }}$ Int. Conf. on Enhanced, Compact and Ultra-Compact Heat Exchangers: From Microscale Phenomena to Industrial Applications, Heredia, Costa Rica, 13-18 September, 2009.

[20] Consolini, L., Thome, J. R. (2009), Micro-channel flow boiling heat transfer of R134a, R236fa, and R245fa, Microfluid Nanofluid, 6, 731 - 746.

[21] Ohta, H., Inoue, K., Ando, M., Watanabe, K. (2009), Experimental investigation on observed scattering in heat transfer characteristics for flow boiling in small diameter tube, Heat Transfer Engineering, 30 (1-2), 19 - 27.

[22] Saiz Jabardo, J. M., Ribatski G., Stelute E. (2009), Roughness and surface material effects on nucleate boiling heat transfer from cylindrical surfaces to refrigerants R-134a and R123, Experimental Thermal and Fluid Science, 33, 579 - 590.

[23] Owhaib, W., Martin-Callizo, C., Palm, B. (2004), Evaporative heat transfer in vertical circular microchannels, Applied Thermal Engineering, 24, 1241 - 1253.

[24] Martin-Callizo, C, Ali, R., Palm, B. (2007), New experimental results on flow boiling of $\mathrm{R} 134 \mathrm{a}$ in a vertical microchannel, The $10^{\text {th }}$ UK National Heat Transfer Conference, $10-11$ September, Edinburgh.

[25] Shiferaw, D., Karayiannis, T. G., Kenning, D. B. R. (2009), Flow boiling in a $1.1 \mathrm{~mm}$ tube with R-134a: experimental results and comparison with model, Int. J. of Thermal sciences, $48,331-341$.

[26] Mahmoud, M. M., Kenning, D. B. R. Karayiannis, T. G. (2009), Single and two phase heat transfer and pressure drop in a $0.52 \mathrm{~mm}$ vertical metallic tube, $7^{\text {th }}$ Int. Conference on Enhanced, Compact and Ultra-Compact Heat Exchangers: From Microscale Phenomena to Industrial Applications, September 13 - 18, Heredia, Costa Rica.

[27] Ong, C. L., Thome, J. R. (2009), Flow boiling heat transfer of R-134a, R-236fa and R$245 \mathrm{fa}$ in a horizontal $1.03 \mathrm{~mm}$ circular channel, Experimental Thermal and Fluid Science, 33, $651-663$.

[28] Kandlikar, S. G. Spiesman, P. H. (1998), Effect of surface finish on flow boiling heat transfer, American Society of Mechanical Engineers, Heat Transfer Division (Publication), 1998.

[29] Qi, S. L., Zhang, P., Wang, R. Z., Xu, L. X. (2007), Flow boiling of liquid nitrogen in micro-tubes: part I - the onset of nucleate boiling, two-phase flow instability and two-phase flow pressure drop, Int. J. of Heat and Mass Transfer, 50, 4999 - 5016. 
[30] Huo, X., Tian, Y. S, Karayiannis, T. G. (2007), R-134a flow boiling heat transfer in small diameter tubes, Advances in compact heat exchangers, R. T., Edwards, Inc., chapter 5, $95-111$.

[31] Coleman, H. W., Steele, W. G. (1999), Experimentation and uncertainty analysis for engineers, $2^{\text {nd }} e d .$, John Wiley \& Sons Inc., New York.

[32] Blasius, H. (1913), Das Ähnlichkeitsgesetz bei Reibungsvorgängen in Flüssigkeiten, Forchg. Arb. Ing.-Wes., No. 131, Berlin.

[33] Shah, R.K., London, A. L. (1978), Laminar flow forced convection in ducts, In: Irvin TF, Hartnett JP (eds) Advances in Heat Transfer, Academic , New York, 51 - 52, 124 - 128.

[34] Dittus, F.W., Boelter, L.M.K. (1930), Heat transfer in automobile radiators of tubular type, Univ. California Berkeley, Publ. Eng. 2/13, pp. 443-461.

[35] Petukhov, B.S. (1970), Heat transfer and friction in turbulent pipe flow with variable physical properties, In Advances in Heat Transfer Vol. 6, Academic Press, New York, pp. 503-564. 


\section{NOMENCLATURE}

$\begin{array}{ll}A & \text { Area, } \mathrm{m}^{2} \\ c_{p} & \text { Specific heat, J/kg K } \\ D & \text { Diameter, } \mathrm{m} \\ f & \text { Fanning friction factor, dimensionless } \\ G & \text { Mass flux, } \mathrm{kg} / \mathrm{m}^{2} \mathrm{~s} \\ h & \text { Specific enthalpy, } \mathrm{J} / \mathrm{kg} \\ h_{f g} & \text { Latent heat, } \mathrm{J} / \mathrm{kg} \\ I & \text { Current, A } \\ k & \text { Thermal conductivity, W/m K } \\ L & \text { Length, } \mathrm{m} \\ \dot{m} & \text { Mass flow rate, } \mathrm{kg} / \mathrm{s}\end{array}$

\section{Subscripts}

$\begin{array}{ll}c & \text { Cross section } \\ f & \text { Fluid } \\ f, \text { in } & \text { Fluid inlet } \\ i & \text { inner } \\ \text { in } & \text { Inlet } \\ m & \text { Measured } \\ o & \text { Outer } \\ p & \text { Pressure drop } \\ s & \text { Surface } \\ s a t & \text { Saturation } \\ s u b & \text { Sub-cooled } \\ s p & \text { Single phase } \\ t p & \text { Two phase } \\ w i & \text { Inner wall } \\ w o & \text { Outer wall }\end{array}$

$\mathrm{Nu} \quad$ Nusselt number $=h D / k$, dimensionless

$P \quad$ Pressure, $\mathrm{Pa}$

$q^{\prime \prime} \quad$ Heat flux, $\mathrm{W} / \mathrm{m}^{2}$

$Q_{\text {Loss }} \quad$ Thermal heat loss, W

$q_{v} \quad$ Volumetric heat generation, $\mathrm{W} / \mathrm{m}^{3}$

Re Reynolds number $=G D / \mu$, dimensionless

$T \quad$ Temperature, $\mathrm{K}$

V Voltage, $\mathrm{V}$

$x \quad$ Thermodynamic vapour quality, dimensionless

$\mathrm{Z} \quad$ Axial position, $\mathrm{m}$

\section{Greek Symbols}

$\alpha \quad$ Heat transfer coefficient, $\mathrm{W} / \mathrm{m}^{2} \mathrm{~K}$

$\Delta \quad$ Chang

$\mu \quad$ Dynamic viscosity, Pa s

$\rho \quad$ Density, $\mathrm{kg} / \mathrm{m}^{3}$ 


\section{List of Figures}

[1] Comparison between the behaviour of the local heat transfer coefficient versus local quality measured by different laboratories using stainless steel tubes having inner diameter of about 0.5 and $1 \mathrm{~mm}$.

[2] Schematic diagram for the test section

[3] Steady state oscillations in (a) mass flow rate and (b) wall temperatue for D $=1.1 \mathrm{~mm}$ and $\mathrm{L}=150 \mathrm{~mm}$ at $\mathrm{P}=6$ bar and $\mathrm{G}=300 \mathrm{~kg} / \mathrm{m}^{2} \mathrm{~s}$ as a function of heat flux

[4] Single phase validations of the investigated tubes in the laminar and turbulent regimes; (a) the friction factor in the welded tube, (b) the average heat transfer in the welded tube, (c) the friction factor in the seamless cold drawn tube, (d) the average heat transfer coefficient in the seamless cold drawn tube.

[5] The effect of heat flux on the local heat transfer coefficient as a function of local vapour quality and distance at $\mathrm{P}=8$ bar and $\mathrm{G} \approx 300 \mathrm{~kg} / \mathrm{m}^{2}$ for the welded tube.

[6] The effect of heat flux on the local heat transfer coefficient as a function of local vapour quality and axial distance at $\mathrm{P}=8$ bar and $\mathrm{G} \approx 300 \mathrm{~kg} / \mathrm{m}^{2}$ s for the seamless tube.

[7] The heat transfer coefficient at three axial locations as a function of heat flux for: (a) the welded tube and (b) the seamless cold drawn tube.

[8] The effect of mass flux on the local heat transfer coefficient at $\mathrm{q} \approx 41 \mathrm{~kW} / \mathrm{m}^{2}$ for (a) the welded tube and (b) the seamless tube.

[9] Effect of mass flux on the heat transfer coefficient at three axial locations for (a) the welded tube, (b) the seamless cold drawn tube.

[10] The boiling curves plotted through increasing heat flux at thee axial locations for the welded and seamless tubes: (a) at location near from entry region, (b) at middle location, (c) at location near from exit, (d) pictures 1 and 3 show the first bubbles observed and pictures 2 and 4 show the pattern at the onset of nucleate boiling.

[11] SEM analysis for the inner surface of (a) welded tube of $1.16 \mathrm{~mm}$ diameter and (b) seamless cold drawn tube of $1.1 \mathrm{~mm}$ diameter.

[12] The wall temperature trends versus axial distance for (a) single phase at low Reynolds number, (b) single phase flow in the transition region, (c) boiling flow.

[13] Reproducibility of the experimental data for (a) the welded tube and (b) the seamless cold drawn tube at $\mathrm{P}=8$ bar and $\mathrm{G}=300 \mathrm{~kg} / \mathrm{m}^{2} \mathrm{~s}$. 


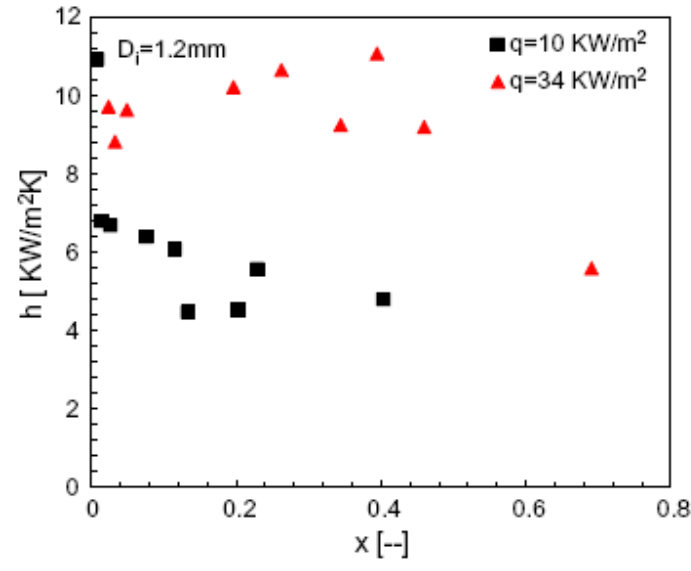

(a) $\mathrm{D}=1.224 \mathrm{~mm}, \mathrm{~L}=220 \mathrm{~mm}, \mathrm{~T}_{\text {sat }}=34$, $\mathrm{G}=200 \mathrm{~kg} / \mathrm{m}^{2} \mathrm{~s}$, Owhaib et al. [23]

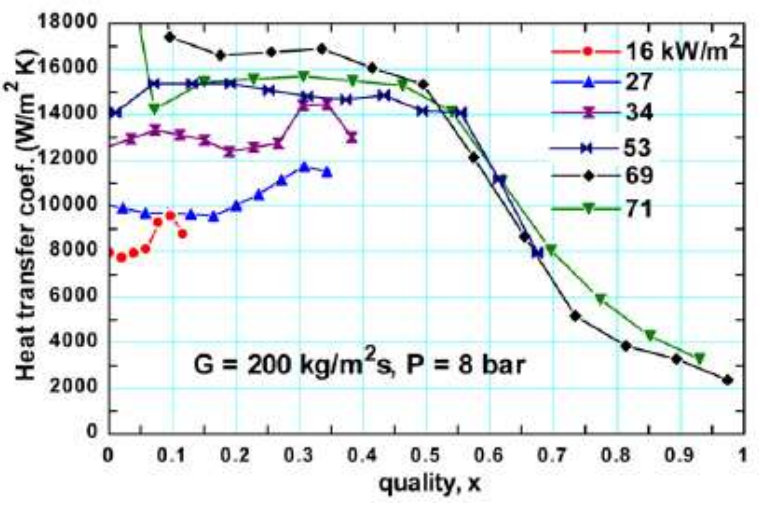

(c) $\mathrm{D}=1.1 \mathrm{~mm}, \mathrm{~L}=150 \mathrm{~mm}, \mathrm{~T}_{\mathrm{sat}}=31{ }^{\circ} \mathrm{C}$, Shiferaw et al.[25]

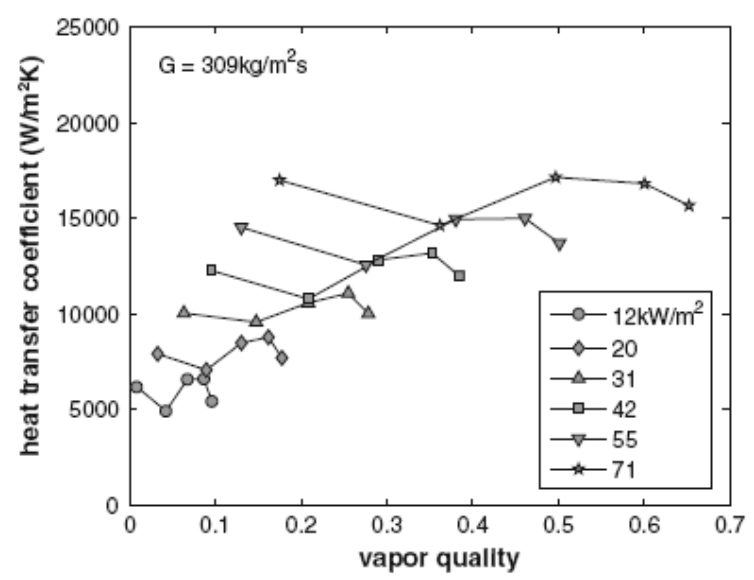

(e) $\mathrm{D}=0.51 \mathrm{~mm}, \mathrm{~L}=79 \mathrm{~mm}, \mathrm{~T}_{\mathrm{sat}}=31{ }^{\circ} \mathrm{C}$, Consolini and Thome [20]

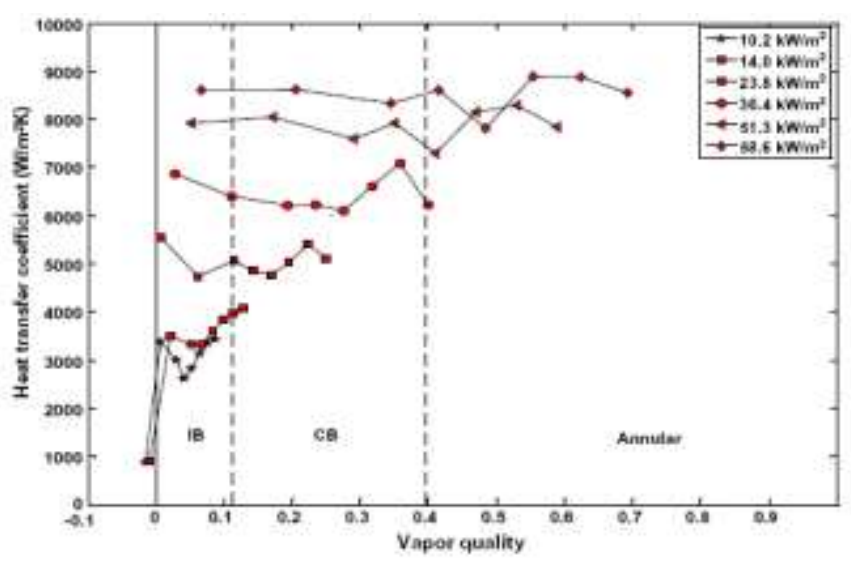

(b) $\mathrm{D}=1.03 \mathrm{~mm}, \mathrm{~L}=180 \mathrm{~mm}, \mathrm{~T}_{\mathrm{sat}}=31{ }^{\circ} \mathrm{C}, \mathrm{G}=300 \mathrm{~kg} / \mathrm{m}^{2} \mathrm{~s}$, Ong and Thome [27]

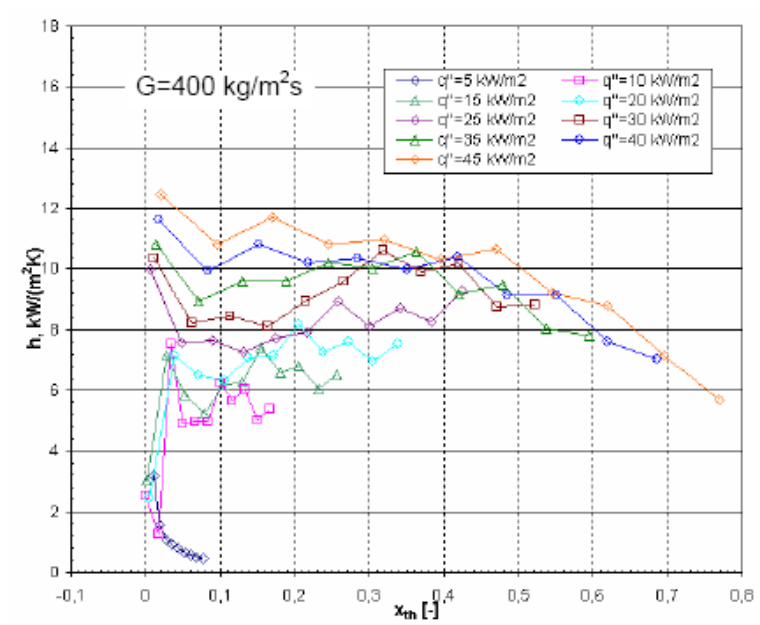

(d) $\mathrm{D}=0.64 \mathrm{~mm}, \mathrm{~L}=213 \mathrm{~mm}, \mathrm{~T}_{\mathrm{sat}}=35{ }^{0} \mathrm{C}$, Martin-Callizo et al. [24]

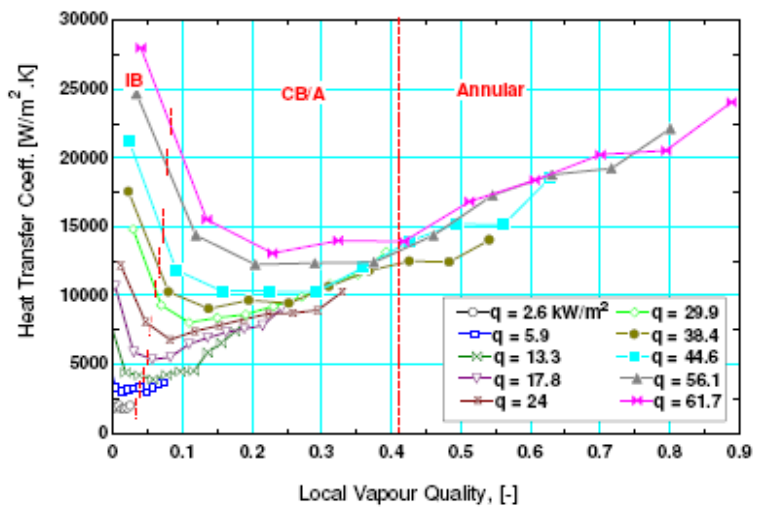

(f) $\mathrm{D}=0.52 \mathrm{~mm}, \mathrm{~L}=100 \mathrm{~mm}, \mathrm{G}=280 \mathrm{~kg} / \mathrm{m}^{2} \mathrm{~s}$, $\mathrm{T}_{\text {sat }}=21{ }^{0} \mathrm{C}$, Mahmoud et al. [26]

Fig. 1 Comparison between the behaviour of the local heat transfer coefficient versus local quality measured by different laboratories using stainless steel tubes having inner diameter of about 0.5 and $1 \mathrm{~mm}$. 


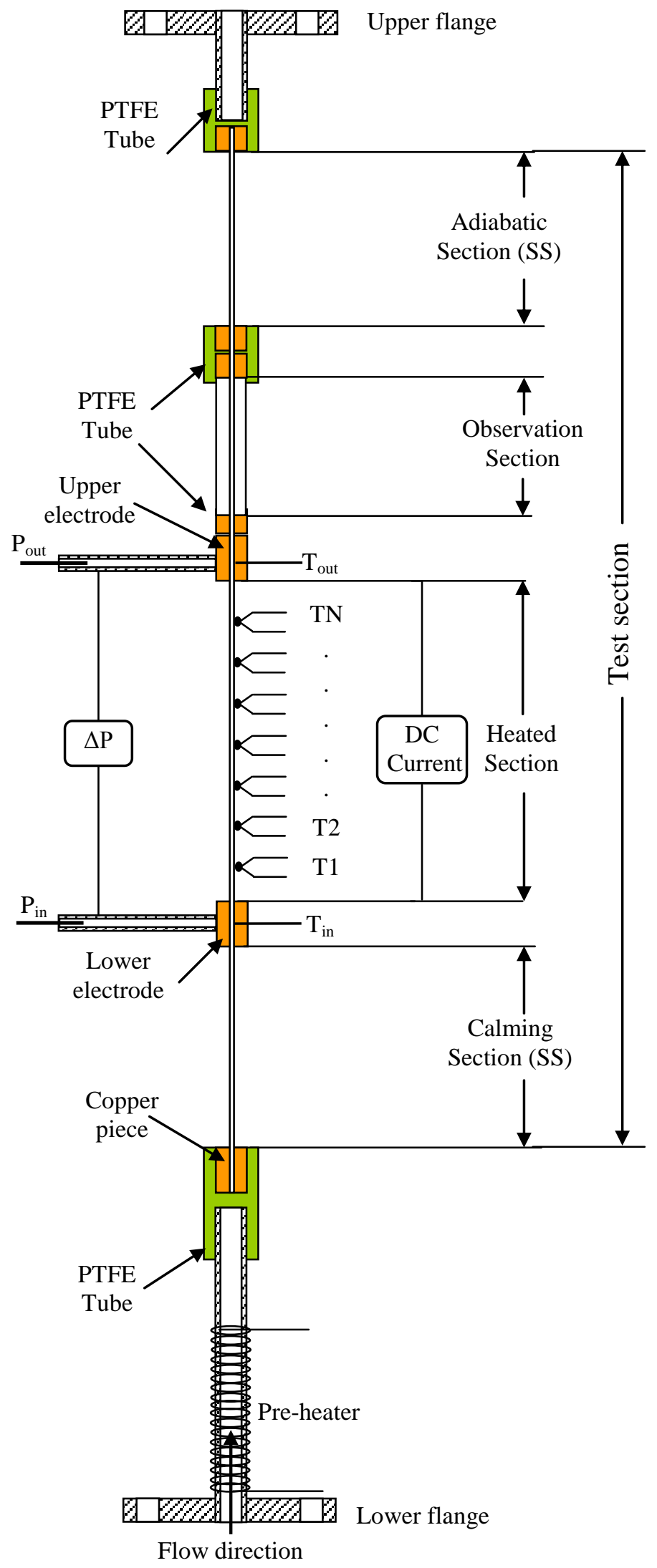

Fig. 2 Schematic diagram for the test section with SS means stainless steel 


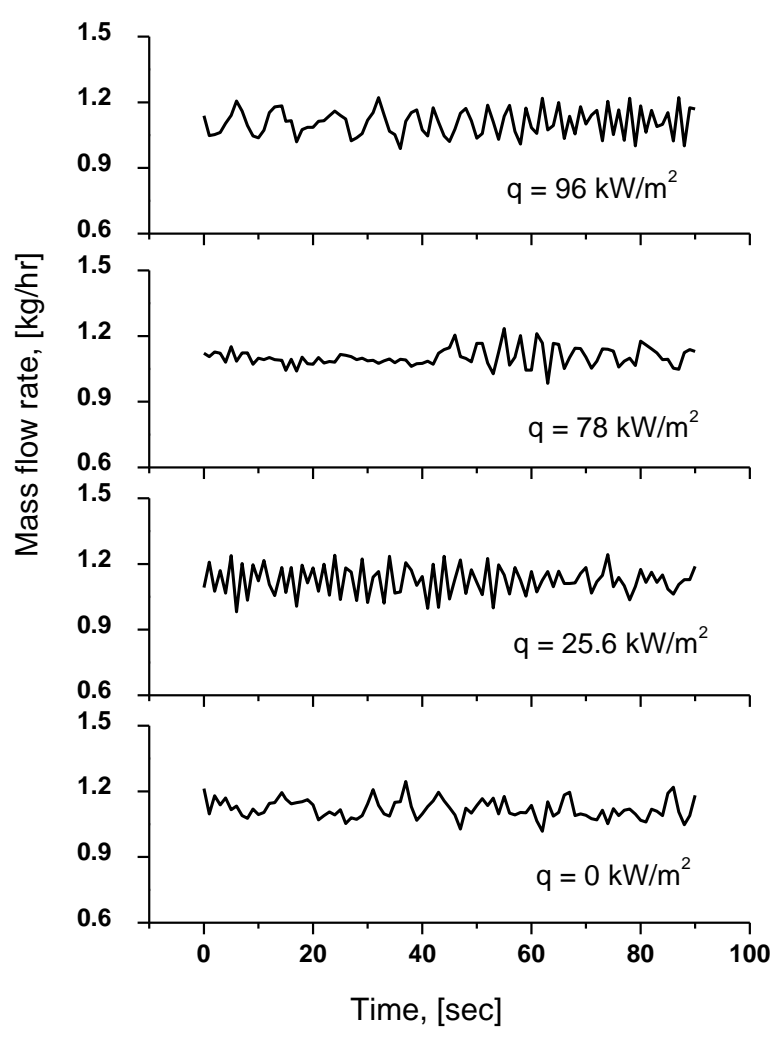

(a)

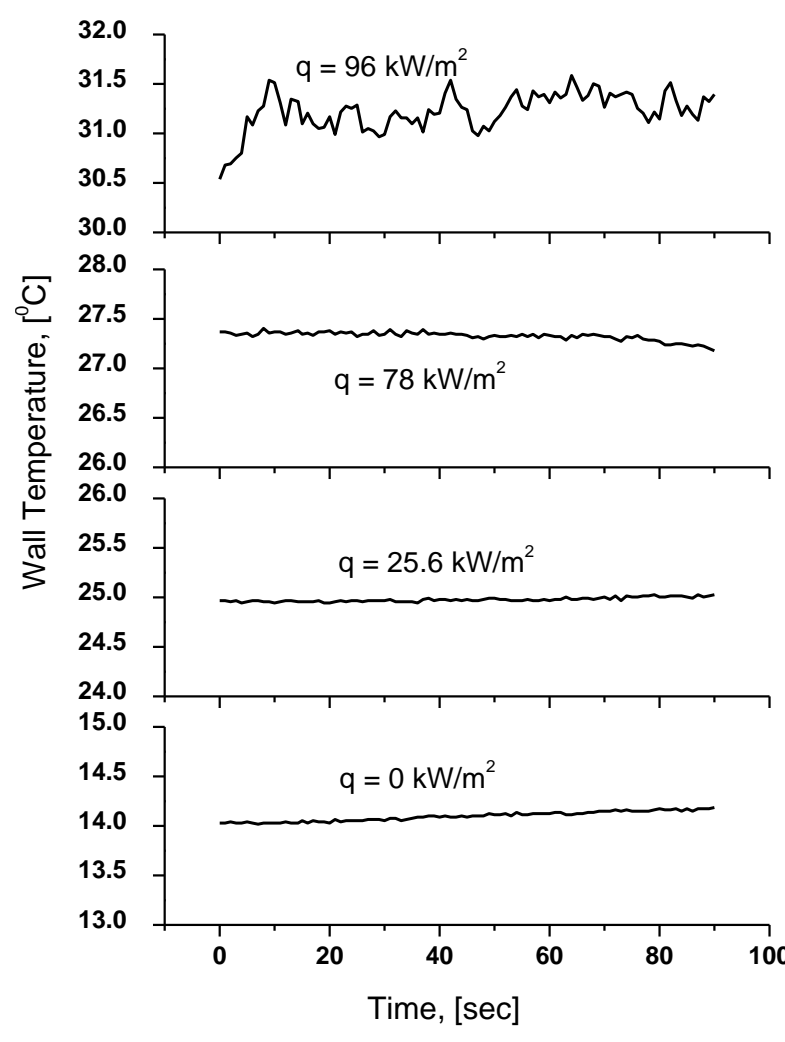

(b)

Fig. 3 Steady state oscillations in (a) mass flow rate and (b) wall temperature for $D=1.1 \mathrm{~mm}$ and $\mathrm{L}=150 \mathrm{~mm}$ at $\mathrm{P}=6$ bar and $\mathrm{G}=300 \mathrm{~kg} / \mathrm{m}^{2} \mathrm{~s}$ as a function of heat flux 


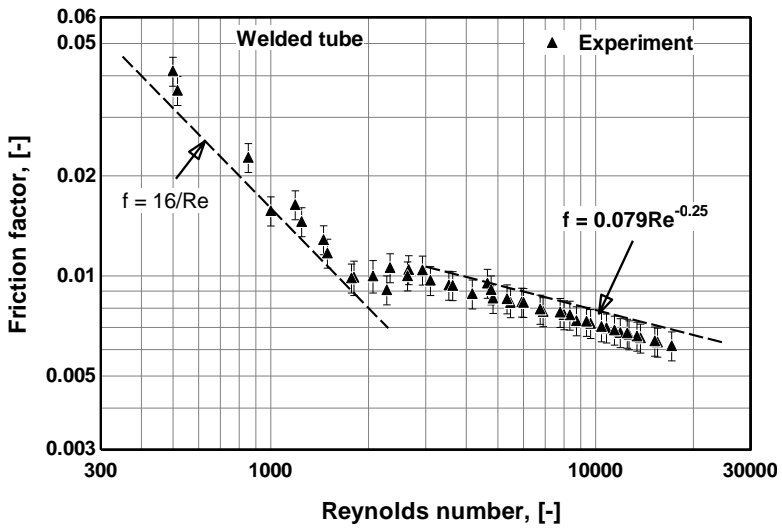

(a)

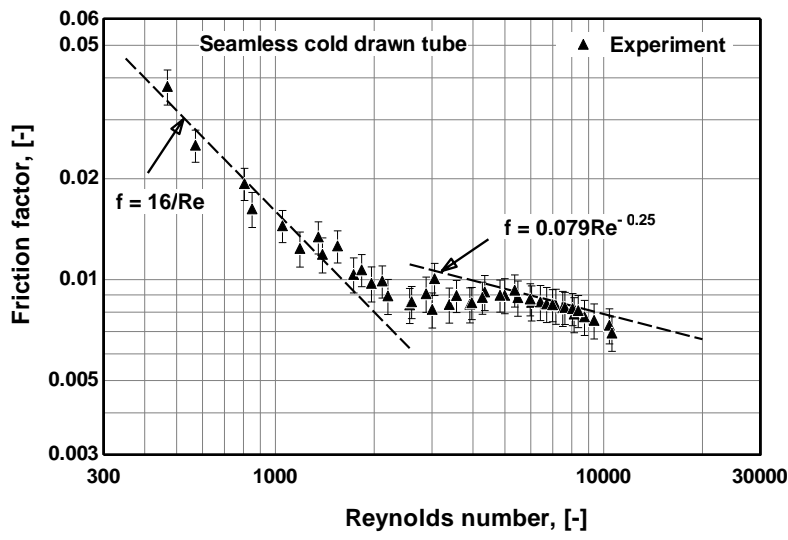

(c)

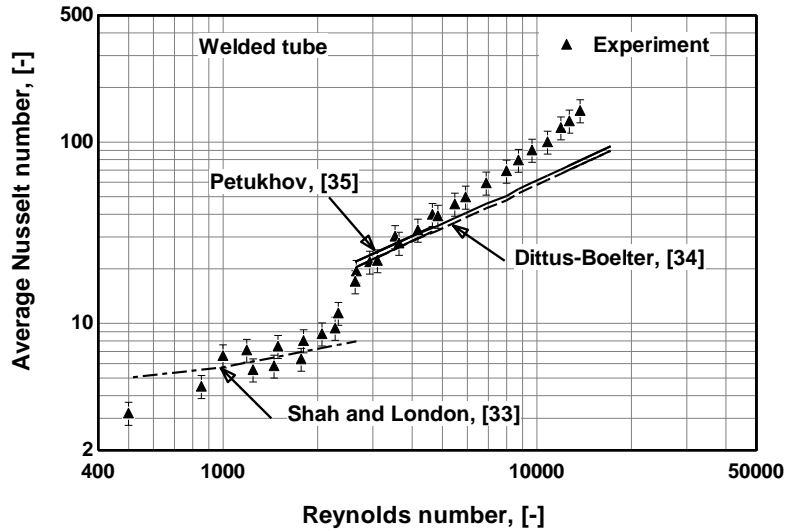

(b)

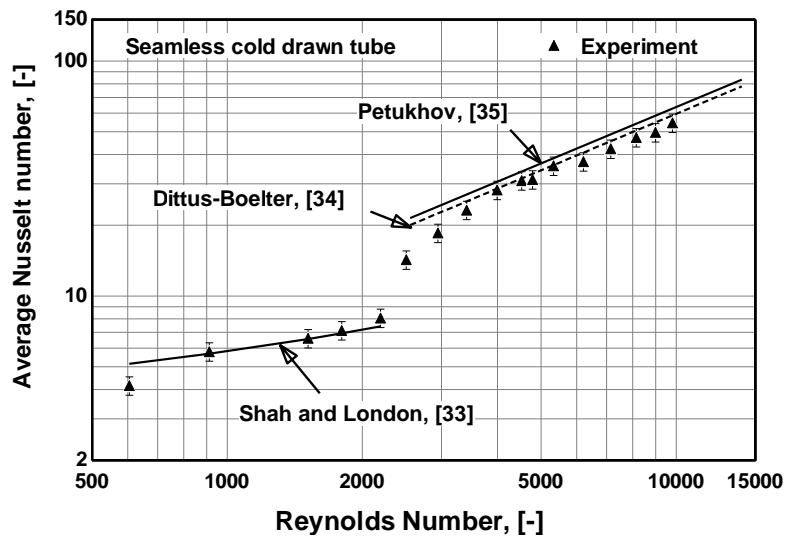

(d)

Fig. 4 Single phase validations of the investigated tubes in the laminar and turbulent regimes; (a) the friction factor in the welded tube, (b) the average heat transfer in the welded tube, (c) the friction factor in the seamless cold drawn tube, (d) the average heat transfer coefficient in the seamless cold drawn tube. 


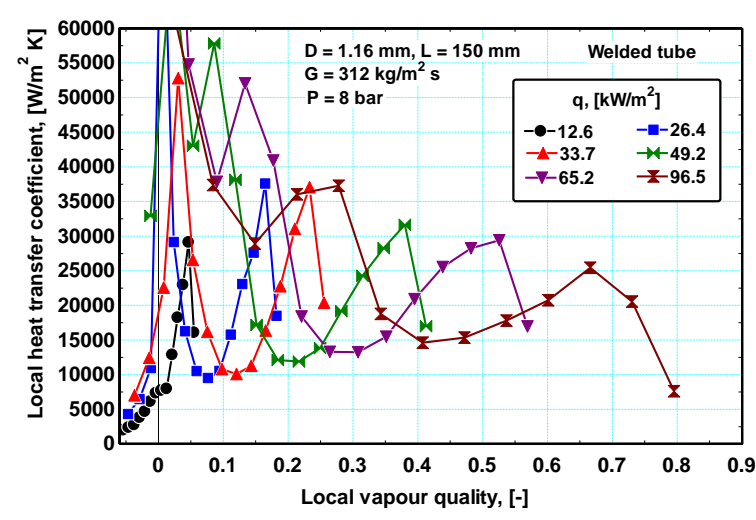

(a)

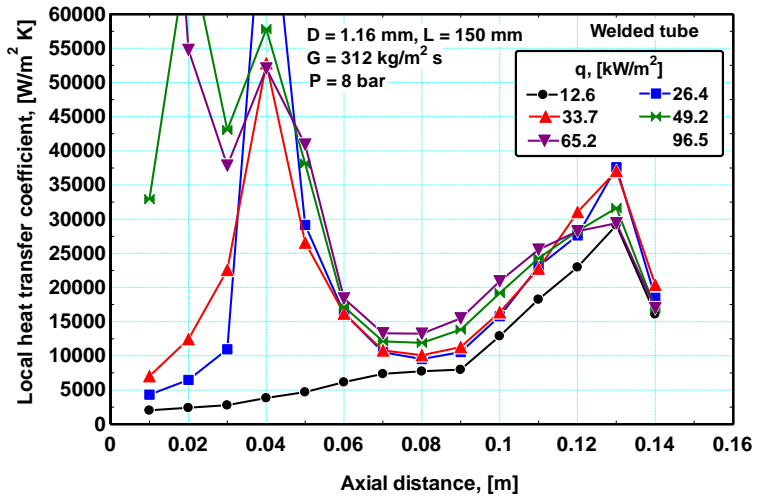

(b)

Fig. 5 The effect of heat flux on the local heat transfer coefficient as a function of local vapour quality and distance at $\mathrm{P}=8 \mathrm{bar}$ and $\mathrm{G} \approx 300 \mathrm{~kg} / \mathrm{m}^{2}$ for the welded tube. 


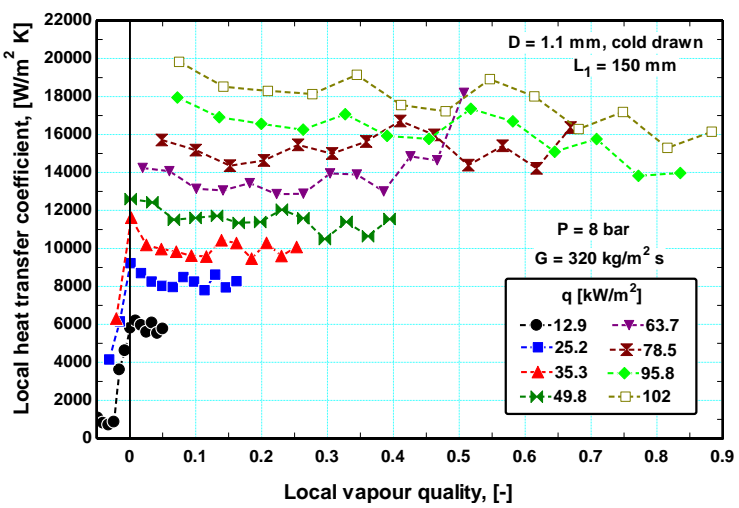

(a)

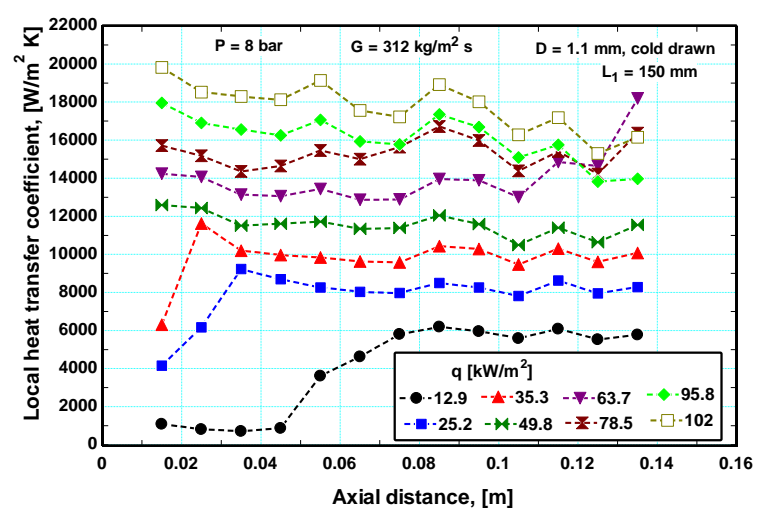

(b)

Fig. 6 The effect of heat flux on the local heat transfer coefficient as a function of local vapour quality and axial distance at $\mathrm{P}=8$ bar and $\mathrm{G} \approx 300 \mathrm{~kg} / \mathrm{m}^{2} \mathrm{~s}$ for the seamless tube. 


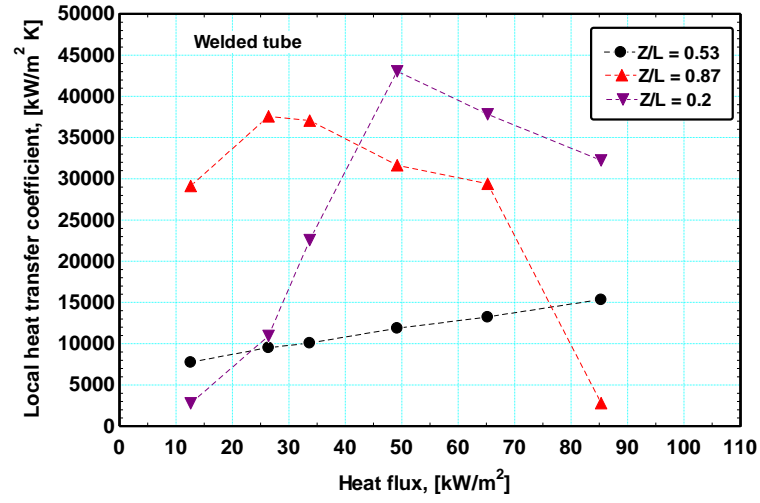

(a)

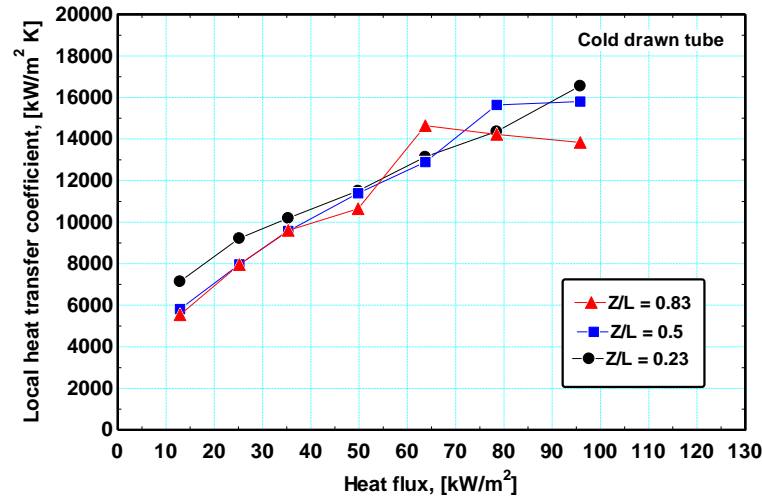

(b)

Fig. 7 The heat transfer coefficient at three axial locations as a function of heat flux for: (a) the welded tube and (b) the seamless cold drawn tube. 

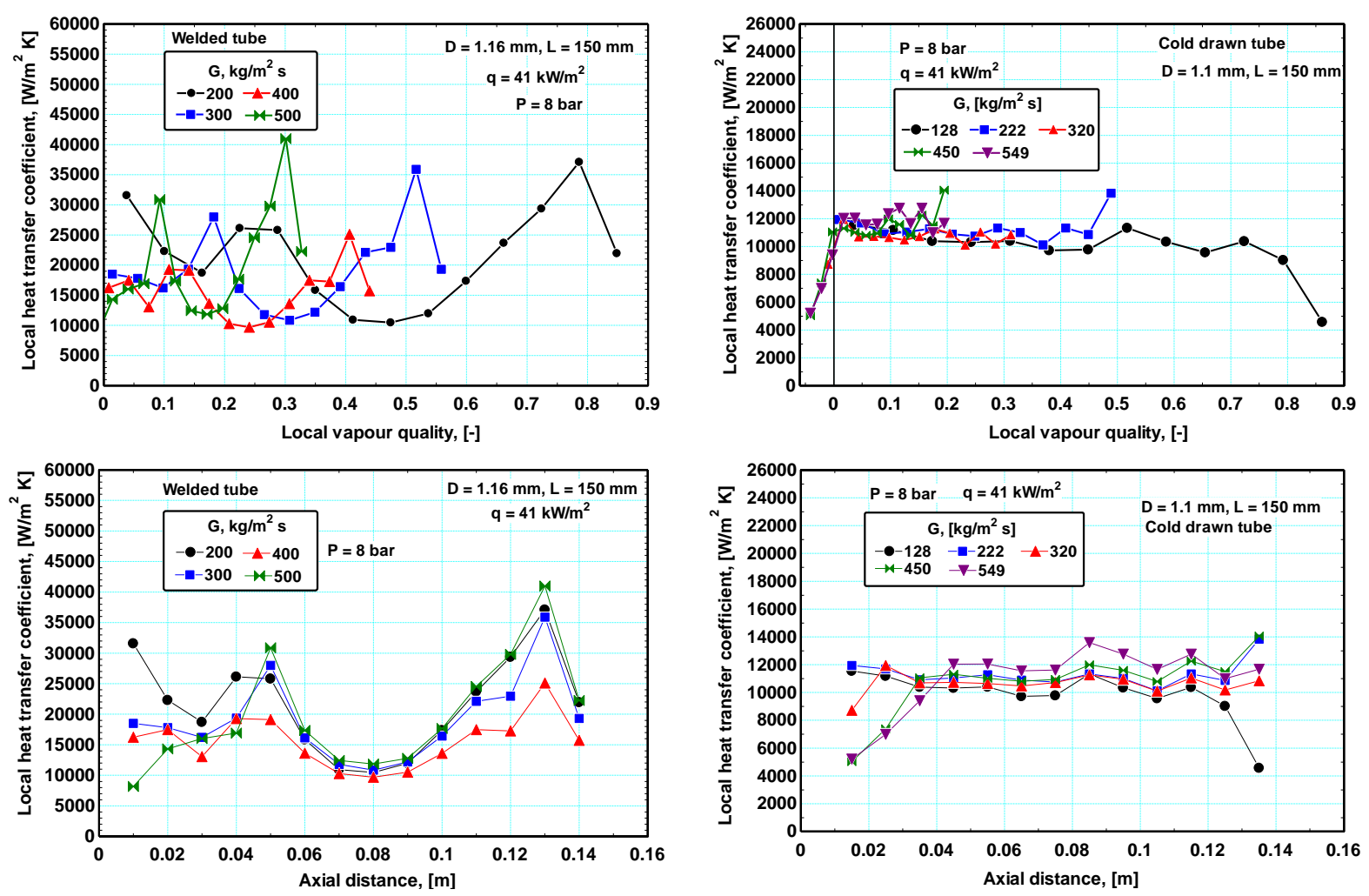

(a)

(b)

Fig. 8 The effect of mass flux on the local heat transfer coefficient at $\mathrm{q} \approx 41 \mathrm{~kW} / \mathrm{m}^{2}$ for (a) the welded tube and (b) the seamless tube. 


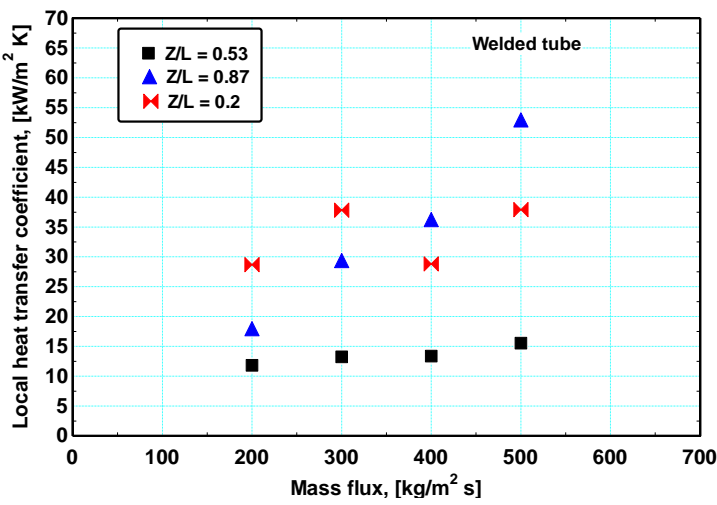

(a)

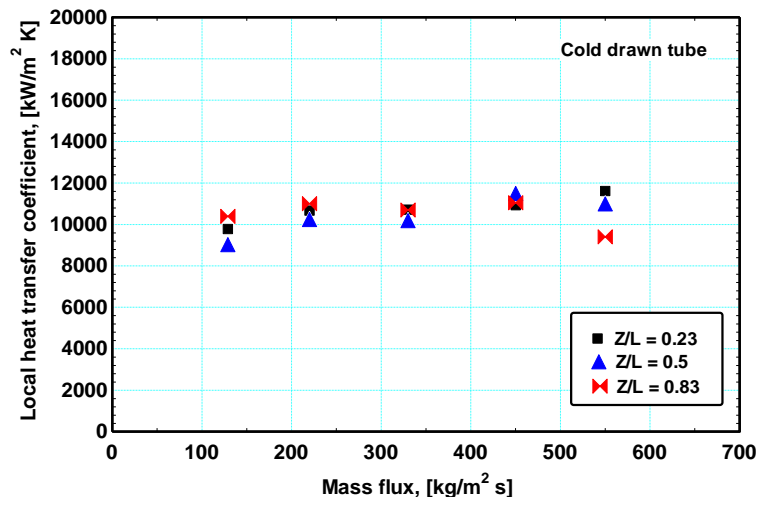

(b)

Fig 9 Effect of mass flux on the heat transfer coefficient at three axial locations for (a) the welded tube, (b) the seamless cold drawn tube. 


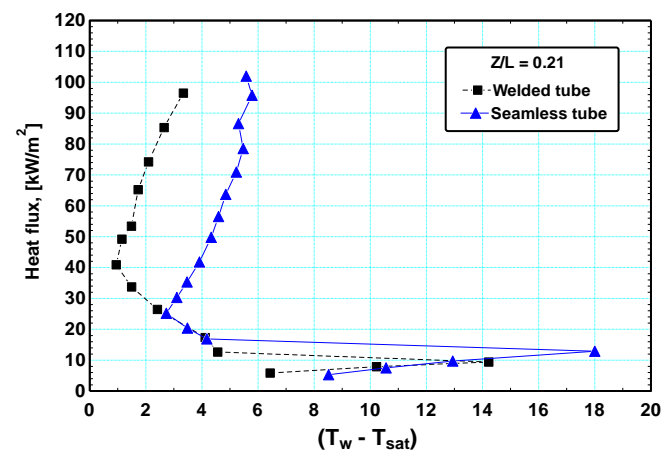

(a)

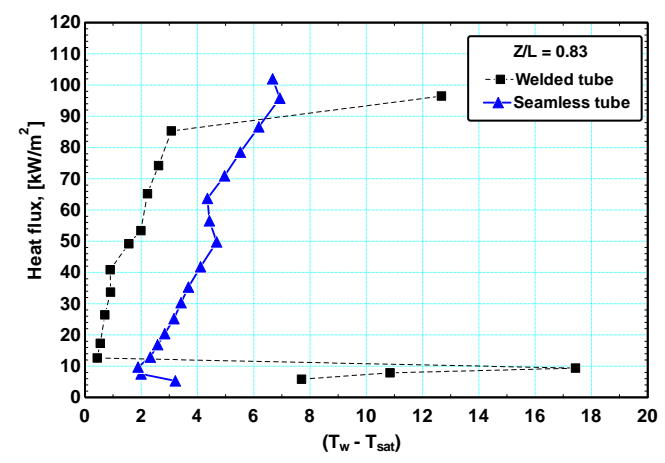

(c)

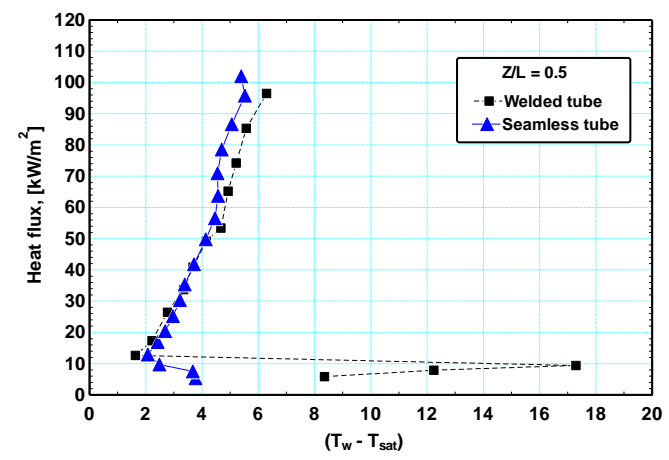

(b)
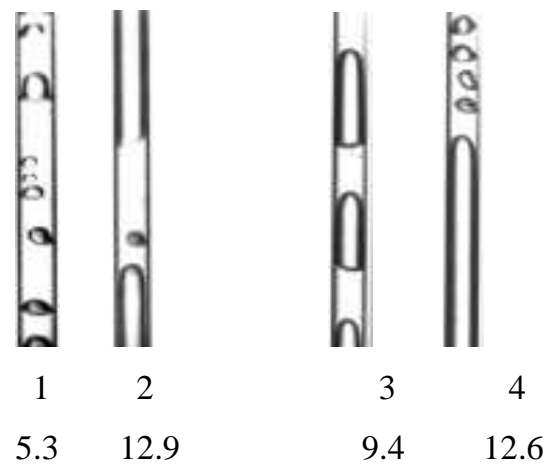

$\mathrm{kW} / \mathrm{m}^{2}$

Seamless tube

(d)

Fig. 10: The boiling curves plotted through increasing heat flux at thee axial locations for the welded and seamless tubes: (a) at location near from entry region, (b) at middle location, (c) at location near from exit, (d) pictures 1 and 3 show the first bubbles observed and pictures 2 and 4 show the pattern at the onset of nucleate boiling 


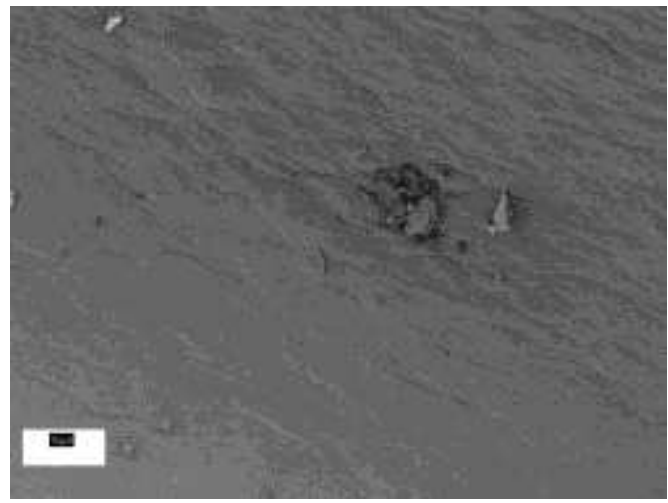

(a)

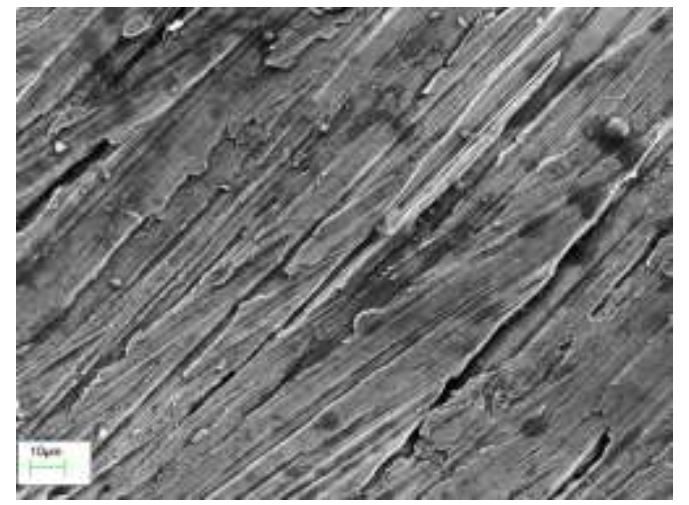

(b)

Fig. 11 SEM analysis for the inner surface of (a) welded tube of $1.16 \mathrm{~mm}$ diameter and (b) seamless cold drawn tube of $1.1 \mathrm{~mm}$ diameter. 


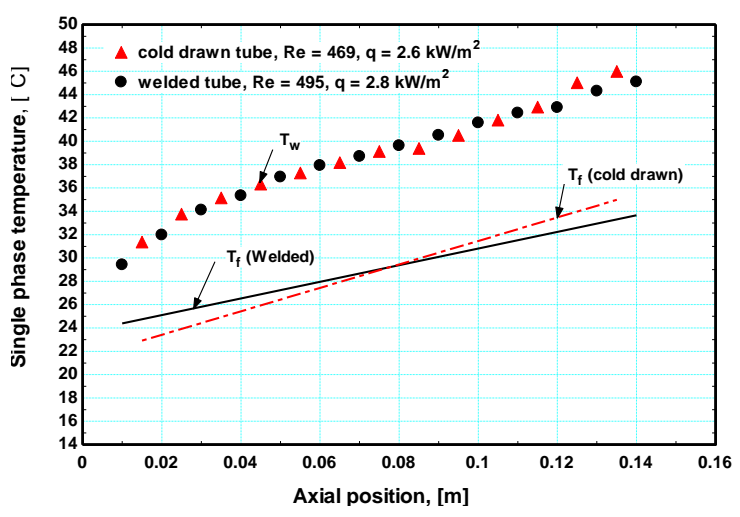

(a)

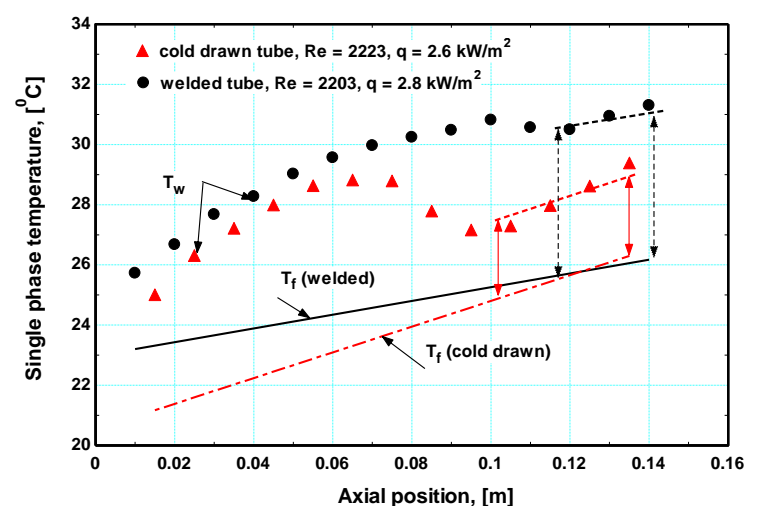

(b)

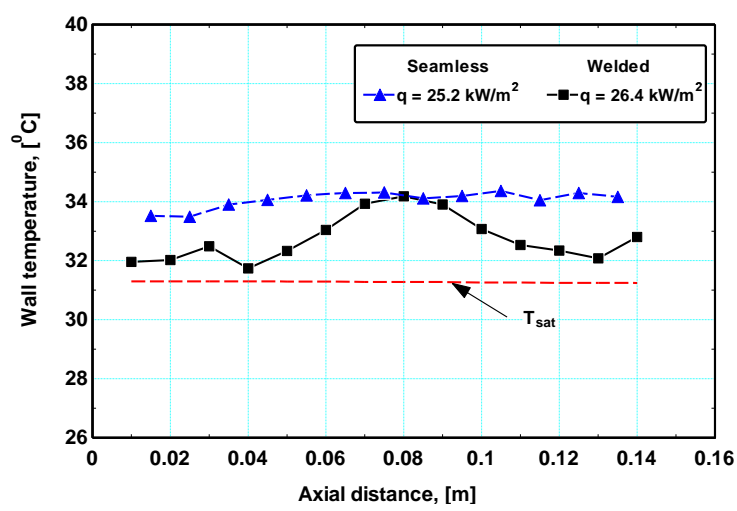

(c)

Fig. 12 The wall temperature trends versus axial distance for (a) single phase at low Reynolds number, (b) single phase flow in the transition region, (c) boiling flow. 


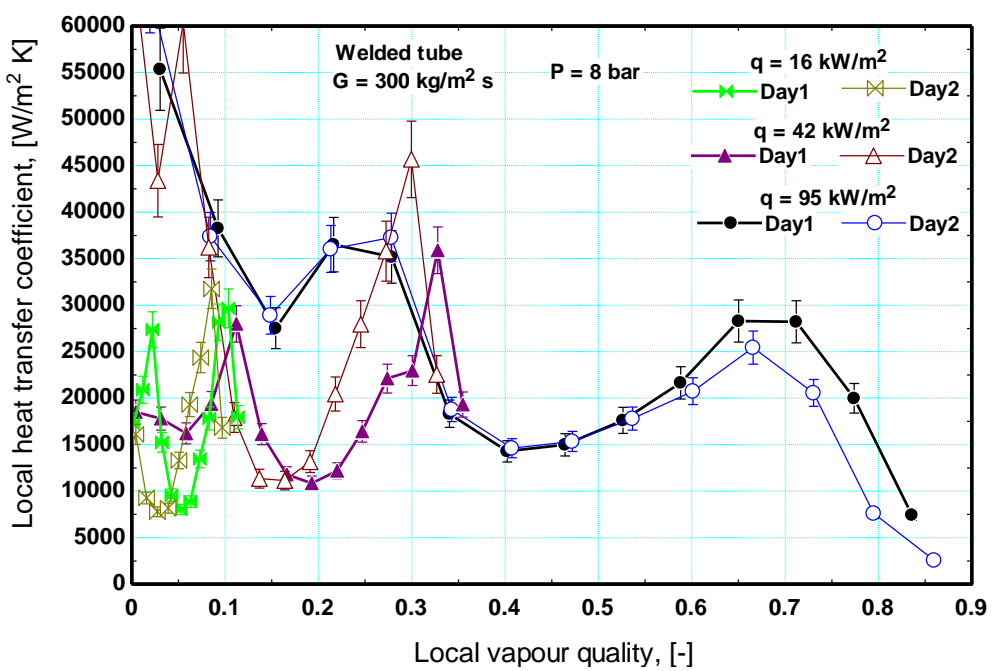

(a)

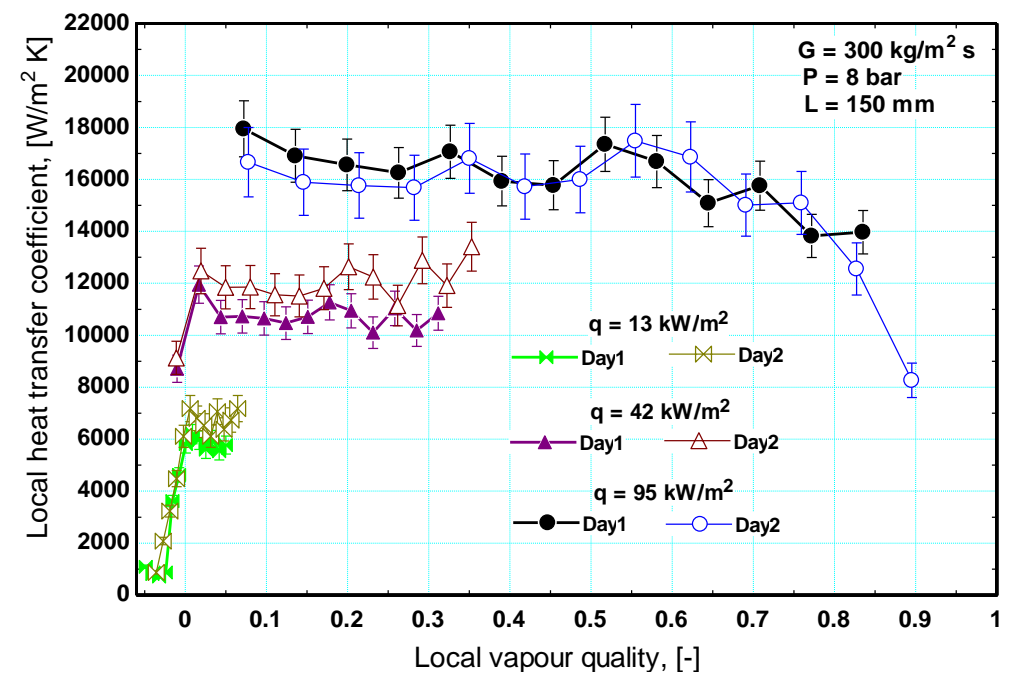

(b)

Figure 13 reproducibility of the experimental data for (a) the welded tube and (b) the seamless cold drawn tube at $\mathrm{P}=8$ bar and $\mathrm{G}=300 \mathrm{~kg} / \mathrm{m}^{2} \mathrm{~s}$. 